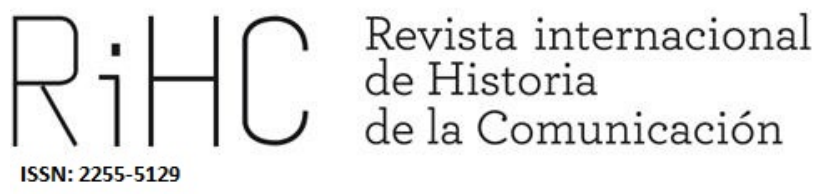

\title{
JULIO CEBRIÁN, ALFONSO ABELENDA Y ÁLVARO CARUNCHO: TRES HUMORISTAS GRÁFICOS GALLEGOS EN MADRID
}

Julio Cebrián, Alfonso Abelenda and Álvaro Caruncho: three Galician cartoonists in Madrid

DOI: http://dx.doi.org/10.12795/RiHC.2019.i13.11

Recibido: 03/10/2019

Aceptado: $10 / 11 / 2019$

Publicado: $15 / 12 / 2019$

Félix Caballero Wangüemert

Universidad de Vigo, España

felixcaballero@hotmail.com

ORCID (iD 0000-0002-0749-9815 
Resumen: En la historia del humor gráfico gallego hay dos nombres fundamentales que no siempre reciben la atención que merecen por haber desarrollado sus carreras en la prensa madrileña: Julio Cebrián y Abelenda. Sin duda, su contribución al humor gráfico español durante las décadas de 1960, 1970 y 1980 fue memorable. Caruncho, casi 20 años más joven, comparte con ellos el haber sido un pintor que se dedicó también durante un tiempo al dibujo de humor por razones más o menos coyunturales y el haberse convertido en uno de los puntales de 'La Codorniz' en la última etapa de la revista. Este artículo pretende rescatar la labor humorística de estos tres dibujantes y poner de manifiesto los paralelismos y cruzamientos de sus trayectorias, especialmente entre Cebrián y Abelenda: los dos empezaron en 'Don José', los dos triunfaron en 'La Codorniz', los dos colaboraron en la prensa diaria madrileña y en otras revistas emblemáticas de la España de su tiempo, los dos fueron Premio Paleta Agromán, etc.

Palabras clave: Abelenda, Julio Cebrián, Caruncho, humor gráfico español, 'La Codorniz', segunda mitad del siglo XX

Abstract: In the history of Galician cartoon there are two main names that have not received the attention they deserve because of having developed their careers in the press of Madrid: Julio Cebrián and Abelenda. Their contribution to Spanish cartoon from to 1990 was great. Caruncho, almost 20 years younger, was also a painter who worked as a cartoonist because of conjunctural reasons and became as them in one of the most important cartoonists of 'La Codorniz' in 1970s. This article aims to rescue the humoristic work of these three cartoonists and to show the parallelisms and crossings of their careers, especially between Cebrián and Abelenda: both started in 'Don José', both suceed in 'La Codorniz', both collaborated in the daily press of Madrid and in some of the most important Spanish magazines, both won Paleta Agromán Prize, etc.

Keywords: Abelenda, Julio Cebrián, Caruncho, Spanish cartoon, 'La Codorniz', second half of the 20th century

\section{Introducción y metodología}

En la historia del humor gráfico gallego hay dos autores a los que no se les ha prestado toda la atención que merecen porque vivieron y trabajaron en Madrid: Abelenda y Julio Cebrián. La labor que realizaron durante las décadas de 1960, 1970 y 1980 hay que incluirla entre lo mejor del humor gráfico español de la época. Especialmente relevante fueron sus viñetas para La Codorniz, pero también es de destacar su producción previa en Don José y posterior para diarios como Arriba, Informaciones, Ya o Pueblo, y revistas como Por Favor, Semana, Cambio 16 o Madriz. En los años 70, otro humorista gallego Caruncho- coincidió con ellos en La Codorniz, completando este trío de gallegos en la vanguardia del humor gráfico madrileño.

El objetivo de esta comunicación es subrayar la contribución de estos tres dibujantes al humor gráfico español de la segunda mitad del siglo XX y poner de manifiesto los paralelismos y cruzamientos de sus trayectorias. 
Para eso se han consultado algunas de las fuentes bibliográficas y hemerográficas existentes sobre los tres humoristas y se han revisado algunas de sus viñetas en La Codorniz y otras revistas, así como las antologías publicados por cada uno de ellos: EI abelendario (Abelenda, 1972), En un periquete (Cebrián, 1973) y iPor narices! (Caruncho, 1977).

\section{Humoristas gallegos en la prensa de Madrid}

El moderno humor gráfico gallego fue fundado por Alfonso Daniel Rodríguez Castelao (1886-1950) en la segunda década del siglo XX, con la serie "Cousa da vida", publicada sucesivamente en los diarios vigueses Galicia, Faro de Vigo y El Pueblo Gallego. Castelao creó una fecunda escuela en la que destacaron otros grandes dibujantes como Carlos Maside (1897-1958), Álvaro Cebreiro (1903-1955), Manuel Torres (1901-1995), Cándido Fernández Mazas (1902-1942), Federico Ribas (1890-1952) o Ignacio Vidales Tomé (1896-1963). Ellos y otros protagonizaron la época dorada de la historia del humor gráfico gallego, no superada todavía, que se vio interrumpida abruptamente por la Guerra Civil.

Durante esos años, los principales humoristas gráficos gallegos fueron reclamados por primera vez para colaborar en lo mejor de la prensa madrileña, sobre todo en El Sol, el principal diario español de la época, donde Castelao colaboró de 1918 a 1922 y Maside, Cebreiro y Torres publicaron viñetas en gallego en la sección "Los maestros de la historieta". Ribas, por su parte, fue un asiduo ilustrador de los periódicos y las revistas de Madrid, como $A B C$ y Blanco y Negro. Antes había colaborado también en la prensa argentina, particularmente en Caras y Caretas.

A partir de 1955, se inicia una nueva etapa en la que los humoristas gallegos van a estar presentes en la prensa madrileña. Julio Cebrián y Abelenda serán los buques insignia de esta nueva vanguardia gallega en la capital, convirtiéndose en pilares de La Codorniz, en los años 60 y 70, aparte de colaborar en otros diarios y revistas. Su trabajo para los periódicos y las revistas de Madrid se prolongará durante más de cuarenta años. A ellos hay que sumar desde 1966 a otros dibujantes como Quesada, Xaquín Marín y Caruncho, que coincidirán con Cebrián y Abelenda en La Codorniz, además de colaborar en otras publicaciones. 


\section{Julio Cebrián, Abelenda y Caruncho. Breves apuntes biográficos}

Julio Cebrián Villagómez nació en A Rúa-Petín, Ourense, el 1 de enero de 1929 y murió en Madrid el 3 de noviembre de 2016, a los 87 años. Desde comienzos de la década de 1950 vivió en la capital de España, donde estudió Derecho y -por poco tiempo- en la Escuela de Cine. Comenzó su actividad gráfica haciendo "filmets" (cortometrajes publicitarios que se proyectaban en los cines precediendo a las películas del programa) en Estudios Moro, puntales de la publicidad cinematográfica en España. Fue un pintor único y notable, que se tuvo que entregar a las colaboraciones en prensa como modo de subsistencia hasta acabar enredado en un oficio en el que no le faltó el reconocimiento, pero que nunca acabó de colmar sus inquietudes.

Alfonso Pedro Abelenda Escudero nació en A Coruña el 5 de octubre de 1931 y murió en la misma ciudad el 21 de marzo de 2019, también a los 87 años. Su familia materna tenía en la ciudad herculina talleres de mármoles, mosaicos, carpintería, escayola, escultura y talla en granito, que constituyeron un ambiente importante en su formación. Su abuelo materno fue el escultor Saturnino Escudero Monteagudo, y su madre y su padre -médico de la marina civil- pintaban. Empezó Ciencias Exactas en Compostela y Arquitectura en la capital de España, sin terminar ninguna de las dos carreras. Durante su juventud destacó en el deporte -fue campeón de España de 110 y 400 metros vallas y miembro del equipo de rugby de la Escuela de Arquitectura de Madrid, llegando a competir internacionalmente-, y actuó de especialista y figurante durante su juventud en algunas películas estadounidenses rodadas en España, como Alejandro Magno (Robert Rossen, 1956), Rey de reyes (Nicholas Ray, 1961) y El coloso de Rodas (Sergio Leone, 1961). Perteneció a la generación de Los Insurgentes, los pintores coruñeses de posguerra que se formaron alrededor de la galería de Lino Pérez, cuna de la vanguardia de la provincia. En dicha galería, en el verano de 1955, a los 24 años de edad, realizó su primera exposición individual. Fue uno de los pintores españoles más relevantes de su generación y miembro correspondiente de la Real Academia Gallega de Bellas Artes Nuestra Señora del Rosario desde 2005. Cultivó un expresionismo figurativo, absolutamente vivencial, con una marcada vertiente humorística. "Empecé a hacer humor desde que nací [...] Toda mi obra lleva una carga lógica de humor, con la cual he nacido y de la que nunca me separaré porque no puedo hacerlo" (Penas, 2008: 45), reconocía el propio pintor.

Álvaro de la Iglesia, Caruncho, nació en A Coruña el 23 de abril de 1948 y murió en la misma ciudad el 14 de noviembre de 2011, a los 63 años. Era casi 20 años más joven que Cebrián y Abelenda, pero falleció el primero de los tres. Era primo del también pintor, escultor y grabador Luis Caruncho (A Coruña, 1929-2016). Estudió en la Escuela de Artes y Oficios, denominada hoy Pablo Picasso, donde tuvo como maestro al acuarelista Mariano García Patiño. Publicó sus primeros dibujos en 1968 en La Voz de 
Galicia, ilustrando unos artículos de Antonio Naveira. En 1969 inició su actividad como diseñador gráfico. Después de dirigir el departamento de Arte de una empresa de publicidad, abrió un estudio con el grafista Alfonso Matarranz, hasta que en 1996 decidió dedicarse exclusivamente a la pintura.

\section{Julio Cebrián, Abelenda y Caruncho. Relación con el humor gráfico gallego}

Después de la Guerra Civil, el humor gráfico español entra en una profunda crisis marcada por la censura y la decadencia artística, provocada por la desaparición de los humoristas de la etapa anterior (algunos son asesinados, otros se exilian y el resto tiene que callar). Las pocas viñetas que se publican (los periódicos reducen bruscamente el número de páginas y el humor es eliminado) proceden, en su mayoría, de agencias extranjeras. A partir de mediados de la década de 1950, cuando Julio Cebrián y Abelenda se inician en el género en Madrid (en Don José, que era un suplemento semanal del diario España de Tánger, pero tenía la redacción en la capital de España), el dibujo de humor experimenta también un tímido impulso en Galicia, con el regreso efímero de tres de los grandes nombres de antes de la Guerra -Cebreiro, Torres y Vidales Tomé- y el inicio de las carreras de Lalo (El Pueblo Gallego, 1954), Quesada (Faro de Vigo, 1961) y Atomé (El Ideal Gallego, 1963). Lalo y Quesada son de la misma generación que Julio Cebrián y Abelenda. Lalo nació en 1927, Julio Cebrián en 1929, Abelenda en 1931 y Quesada en 1933. Atomé, sin embargo, es mayor que todos ellos (1914), a pesar de empezar el último. En cualquier caso, en Galicia era imposible profesionalizarse. Atomé, por ejemplo, fue un médico rural que dibujaba viñetas en su tiempo libre, convirtiendo en protagonistas a los paisanos a los que atendía en su consulta, a los que siempre trató, dentro y fuera de sus dibujos, con un respeto y un cariño enormes. Tampoco en Madrid era fácil profesionalizarse, pero si existía alguna posibilidad, era allí.

Quesada se convertirá en seguida en uno de los pilares del resurgimiento del humor gráfico gallego a partir de 1970, además de colaborar con la prensa de Madrid ya desde 1966 (sin instalarse nunca allí ni dejar de dibujar diariamente para Faro de Vigo). En 1970 y 1971 se inician en el oficio -curiosamente también en una publicación de Madrid, pero gallega por entero, por sus artífices, sus contenidos y su nombre, Chan-Siro y Xaquín Marín, que pronto se convertirán en las otras tres patas sobre las que se levantará el humor gráfico gallego en esos años. Nacidos los dos en 1943, tienen 14 y 12 años menos que Julio Cebrián y Abelenda, pero solo cinco más que Caruncho, que, ciertamente, es miembro de una generación posterior a Cebrián y Abelenda. Caruncho vino al mundo en 1948, igual que Xosé Lois, que lleva 37 años dibujando a diario la serie "O 
Carrabouxo" en La Región de Ourense. Ahí es donde debemos ubicarlo generacionalmente.

Ni Cebrián ni Abelenda, ni Caruncho, participaron de la etapa de resurgimiento del humor gráfico gallego, que tuvo lugar durante los años $70 \mathrm{y}$, sobre todo, 80 del siglo pasado, porque no ejercieron el oficio en Galicia, más allá de alguna colaboración ocasional y tardía de Abelenda en El Ideal Gallego y La Opinión A Coruña. Sin embargo, Abelenda y Caruncho asistieron al I Seminario Galego do Humor, celebrado en Sada (A Coruña) el 26 y 27 de junio de 1982, el primero de los grandes acontecimientos relacionados con el humor gráfico que tuvieron lugar en la Comunidad durante ese periodo. Allí estuvieron todos los humoristas gráficos gallegos de la época, incluso algunos literarios. Hay que tener en cuenta que Caruncho vivió siempre en A Coruña (no residió nunca en Madrid, pese a colaborar durante años en La Codorniz) y que por aquella época Abelenda había regresado a la ciudad herculina. Cebrián, por el contrario, continuaba en la capital de España.

\section{Julio Cebrián, Abelenda y Caruncho. Paralelismos y cruzamientos}

\subsection{La pintura}

Cebrián, Abelenda y Caruncho fueron tres pintores que hicieron humor gráfico durante una parte de su vida por razones puramente pragmáticas, alimenticias, aunque en los casos de los dos primeros, sobre todo de Cebrián, esta actividad complementaria llegó a suponer una parte muy importante de su producción artística, prolongándose durante más de 40 años.

\subsection{Don José}

Cebrián y Abelenda se estrenaron como humoristas gráficos en la revista Don José, fundada por Antonio Mingote el 13 de octubre de 1955 como suplemento semanal del diario España, de Tánger (que por aquel entonces tenía estatus de zona internacional, pero con una fuerte influencia de España, que la había ocupado militarmente entre 1940 y 1945), aunque la redacción de la publicación se hallaba emplazada en Madrid, donde 
también se distribuía el periódico1. Duró hasta el 20 de marzo de 1958. Fue una de las pocas revistas de humor que pudo competir con La Codorniz en aquellos años.

Abelenda fue un descubrimiento del propio Mingote, mientras que Cebrián se dio a conocer mediante un envío espontáneo a la sección de "correspondencia" que había en el periódico dedicada a comentar los envíos no solicitados, pero en la que se advertía: "Si ven su trabajo publicado, pasen a cobrar". Así debutaron también Madrigal y Máximo. Cebrián mereció el siguiente comentario: "Sus dibujos son buenos, pero desagradables. Nos quedamos con uno que lo es menos" (Tubau, 1987: 82-83).

Cebrián y Abelenda llegaron a ser los principales dibujantes de la revista, junto a Puig Rosado y Ballesta. En el semanario colaboraron también, entre otros muchos ilustradores y escritores, Madrigal, Máximo, Lorenzo Goñi, Tono, Pablo Núñez, Gila, José Luis Coll, Antonio Ozores, Alfonso Paso, Jaime de Armiñán y Palomino.

Coll -que años después formaría con José Luis Sánchez Polack, Tip, el famoso dúo de humoristas Tip y Coll- recordaba así al Abelenda de Don José:

Conocí a Alfonso Abelenda en la redacción del desaparecido Don José, cuando los que hoy tenemos medio siglo apenas teníamos un cuarto ni un cuarto. Con Ballesta y Puig Rosado formaba un trío de vanguardia en el campo del humor gráfico. Mingote decía de ellos que eran la promesa palpable de ese humor que se hacía entonces tan puro, porque, por prescripción facultativa, no se podía hacer de otra manera. Hice gran amistad con Alfonso que aún conservo como oro en paño. Recuerdo una de sus criaturas, de las primeras por cierto, que conté en infinidad de ocasiones por parecerme un prodigio de ingenio: dos personajes hablan en primer término refiriéndose a otro que pasa al fondo. $Y$ dice uno de ellos: "Allí donde lo ves, el año pasado no tenía un céntimo, y este año ya debe más de doscientos millones". Esta caricatura de cariz rumasiano 2 me dio el promedio, en cierto modo, del talante y el talento de su autor (Mallo, 2001: 178).

\subsection{La Codorniz}

Al desaparecer Don José, Cebrián y Abelenda se incorporaron a La Codorniz de un modo fijo, igual que otros de sus colaboradores, como Puig Rosado y Ballesta.

\footnotetext{
${ }^{1}$ En Tánger se llegaron a editar hasta tres diarios españoles: El Porvenir, África y España (entre 1938 y 1967). El periodista Eduardo Haro Tecglen, vinculado después durante muchos años a El País, fue redactor-jefe de África, en 1946; y director de España, en 1967.

${ }^{2}$ Por Rumasa, grupo de empresas españolas propiedad de la familia Ruiz-Mateos y Jiménez de Tejada, expropiado por el Gobierno español en 1983 por razones de utilidad pública e interés social.
} 
Cebrián trabajó de manera estable para la revista desde el 27 de agosto de 1961 hasta el cierre de la publicación en 1978, aunque colaboraba esporádicamente desde el 22 de enero de 1956.

Además de ocuparse de las tareas de redacción y confección (en esta última tarea, junto a Madrigal y Pablo), hacía chistes de actualidad; escribía una columna de crítica de arte titulada "Plásticos y plastas" con el seudónimo Villagómez (su segundo apellido) en la que "no se cortaba ni en las alabanzas ni en los denuestos" (Madrigal, 2016: 43); y, en una sección muy personal, con el encabezamiento "Retrato chapuza", dibujaba caricaturas alegóricas de personajes famosos con un grafismo de garabatos enrevesados.

Fue el autor de la primera caricatura de un político en activo tras la Guerra Civil: la del entonces ministro de Información y Turismo Manuel Fraga, publicada el 5 de diciembre de 1965 con motivo de la inminente publicación de la ley de prensa que suprimió la censura previa. Fraga llevaba en brazos el texto legal como si fuera un recién nacido. Tres años después, en el número del 27 de octubre de 1968, fue más allá y realizó otra caricatura de todo el consejo de ministros, menos Franco. El lector ocupaba, precisamente, el punto de vista del dictador. Aparecían el vicepresidente del Gobierno, el almirante Luis Carrero Blanco, y el ministro de Justicia, Antonio María de Oriol Urquijo, a la derecha y Fraga y el ministro de Obras Públicas, Federico Silva Muñoz esperando que llegara a presidirlo un generalísimo que por razones obvias no podía aparecer en el dibujo. Tenía riesgo y mérito, porque con la Ley Fraga los límites a la libertad de expresión eran difusos. Xaquín Marín ha calificado esta ley de "una especie de trampa para cazar gente" (Caballero, 2018: 213). Las dos caricaturas -la de Fraga y la del consejo de ministros- fueron portada de la revista.

Abelenda colaboró en La Codorniz entre 1962 y 1977, y se convirtió, con Cebrián, en uno de pocos dibujantes del equipo permanente, al que recordaba así: "La Codorniz era una revista de humor independiente y políticamente variopinta. Había desde rojos perdidos hasta fachas, y todos nos llevábamos muy bien respetando las opiniones personales. Nadie nos corregía excepto la censura, pero a la censura se le colaban muchos goles" (Pereira, 2014).

Caruncho comenzó a dibujar para La Codorniz en 1972, por mediación de su paisano Abelenda, que ya colaboraba en la revista desde una década antes. Vio los chistes que hacía, le gustaron y se los llevó al director de la publicación. Caruncho se convirtió en colaborador fijo hasta que se cerró el semanario y pasó a firmar las viñetas con su segundo apellido, pues su nombre y primer apellido (Álvaro de la Iglesia) coincidían con el del director de la revista, aunque el apellido de éste se escribía parcialmente junto (De Laiglesia). En La Codorniz, el humorista coruñés destacó por sus ilustraciones que mezclaban el surrealismo con la crítica política. 
Caruncho residió siempre en A Coruña. Los chistes los enviaba por correo, aunque iba a Madrid de vez en cuando, lo que le permitió conocer a sus compañeros de revista. En una entrevista publicada por el diario A Opinión A Coruña en febrero de 2008, los evocaba de esta manera:

Aquella época era bárbara. Yo creí que los humoristas eran gentes simpáticas y me encontré con gente rarísima que se ponía verde el uno al otro, tenían un sentido de la crítica tremendo entre ellos. Eran muy especiales y tenían un sentido del humor muy particular. Yo era el más joven de todos, los demás eran señores de unos 70 años. Cebrián, que era de Ourense, era un tipo estupendo, de una gran cultura, y Serafín, el de las marquesas, tenía una mujer que se quedaba con todo el dinero (Bugallal, 2008).

En la década de 1970 también colaboraron en La Codorniz otros dos humoristas gallegos: Quesada y Xaquín Marín, que se estrenó en 1972, como Caruncho. Un tercero, Pepe Carreiro, que estaba iniciándose en el oficio, llegaría a publicar un par de viñetas.

La Codorniz era el buque insignia del humor gráfico español y además, desde la desaparición de Don José, señoreaba prácticamente sin competencia ninguna. Durante los años 60, cuando se incorporan Julio Cebrián y Abelenda, incrementa sus ventas, pero pierde iniciativa, debido en parte a la decadencia física del redactor jefe, Fernando Perdiguero, que morirá en 1970. Frente a la creatividad de las nuevas generaciones, muestra un acusado conservadurismo burgués (Prieto y Moreiro, 1998: 35).

Los años 70, con Caruncho ya incorporado al elenco de colaboradores, son los del declive de la publicación, atribuible a tres causas: 1) la poca adaptación a los cambios sociales y la competencia de Hermano Lobo (creada por Chumy Chúmez en 1972 y que desde el principio la superaría en ventas y prestigio) y de los diarios, con un humor más dinámico y apegado a la actualidad; 2) la muerte de Perdiguero en 1970 y la renuncia de De Laiglesia en 1977; y 3) la censura, que cerrará temporalmente la revista en dos ocasiones: del 11 febrero al 17 junio de 1973, por un rosario de irreverencias, inmoralidades y falta de respeto a lo largo de varios números, aunque la gota que colmó el vaso fue meter en "La cárcel de papel" al entonces secretario general del Movimiento, Torcuato Fernández Miranda; y del 15 junio al 21 septiembre de 1975, por el número extraordinario dedicado a la Universidad, en especial por la portada de Madrigal y un artículo de Santiago Lorén. En la España de la apertura, La Codorniz optó por un tono agresivo pero desconcertado, sin saber "cómo nadar y guardar la ropa" (Prieto y Moreiro, 1998: 35-36).

Tras la dimisión de De Laiglesia en mayo de 1977, la revista inició una nueva etapa, dirigida por Miguel Ángel Flores, con Manuel Summers detrás, y aún otra más, con Fermín Vílchez como director y Máximo y Cándido como animadores (el segundo dirigiría al final la publicación). 
La Codorniz publicó su último número en diciembre de 1978. Era el 1.898: por dos no llegó a los 2.000 .

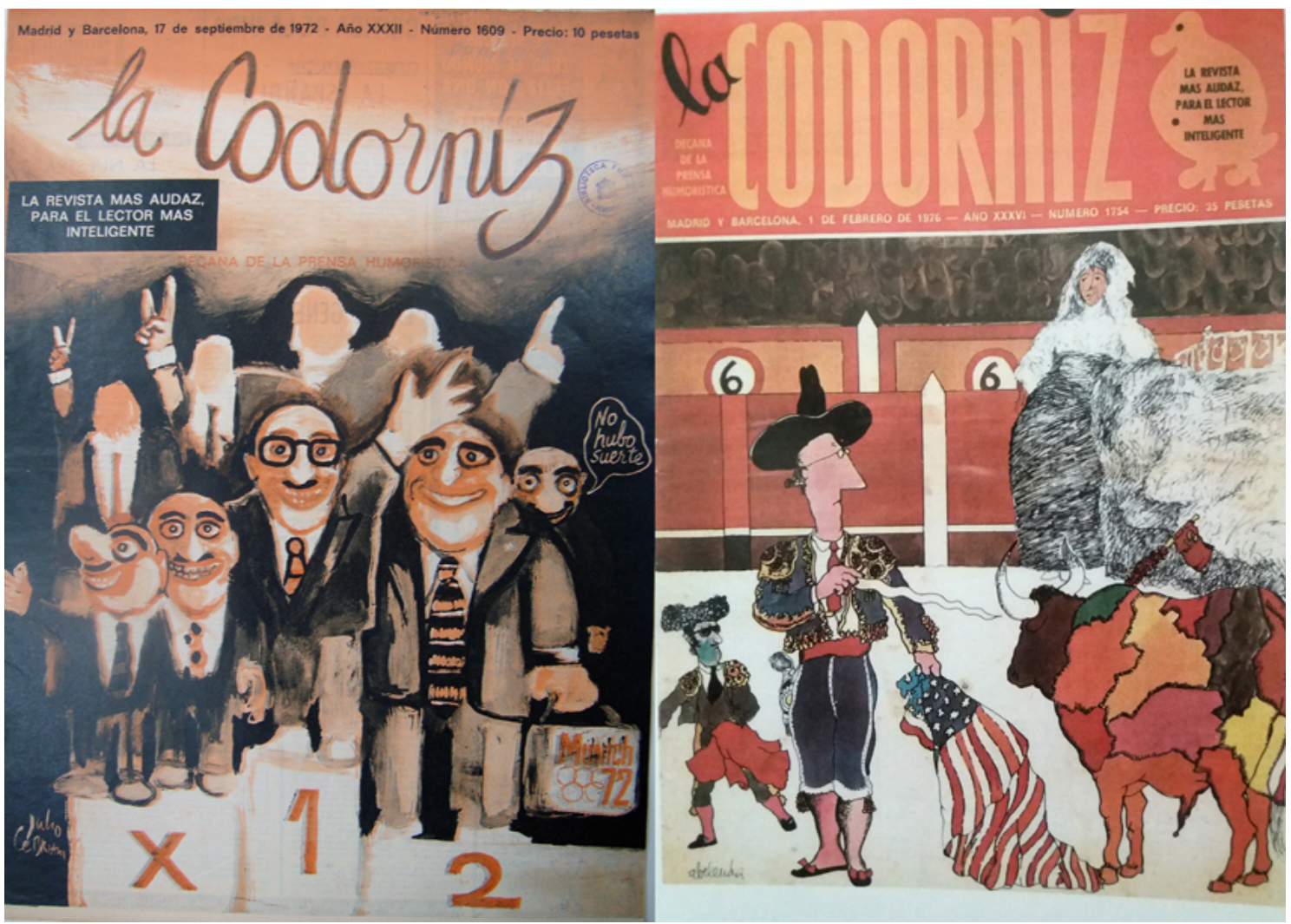

Figura 1. Portadas de Julio Cebrián y Abelenda en La Codorniz (1.609, 17-9-1972, y 1.754, 1-2-1976, respectivamente).

\subsection{Antologías}

En otra cosa que coinciden Cebrián y Abelenda -y también Caruncho- es en la publicación de sendas antologías de su trabajo en La Codorniz.

Los dos primeros publicaron sus libros en la colección "La Nariz", editada por Planeta y dirigida por Álvaro de Laiglesia. Primero lo hizo Abelenda (El abelendario, no 11), en 1972, y al año siguiente, Cebrián (En un periquete, no 19).

El libro de Abelenda fue reeditado en 2013 por la editorial coruñesa Arenas (EI Abelendario. 40 años después). No fue un mero ejercicio de nostalgia, ya que vino a poner de manifiesto que la agresividad de las viñetas del humorista coruñés no había perdido un ápice de actualidad.

También en una editorial coruñesa (Moret), en 1977, publicó Caruncho su único libro de humor gráfico: iPor narices!, prologado por Abelenda, quien escribe: "Caruncho, cruel, puntiagudo, e impenitente desde que era un tierno [...] es un tiernosadomasoca o un 
masocasadotierno o un masocasadotiernista o, como pueden adivinar, un masocatiernosadista" (Caruncho, 1977: 6).
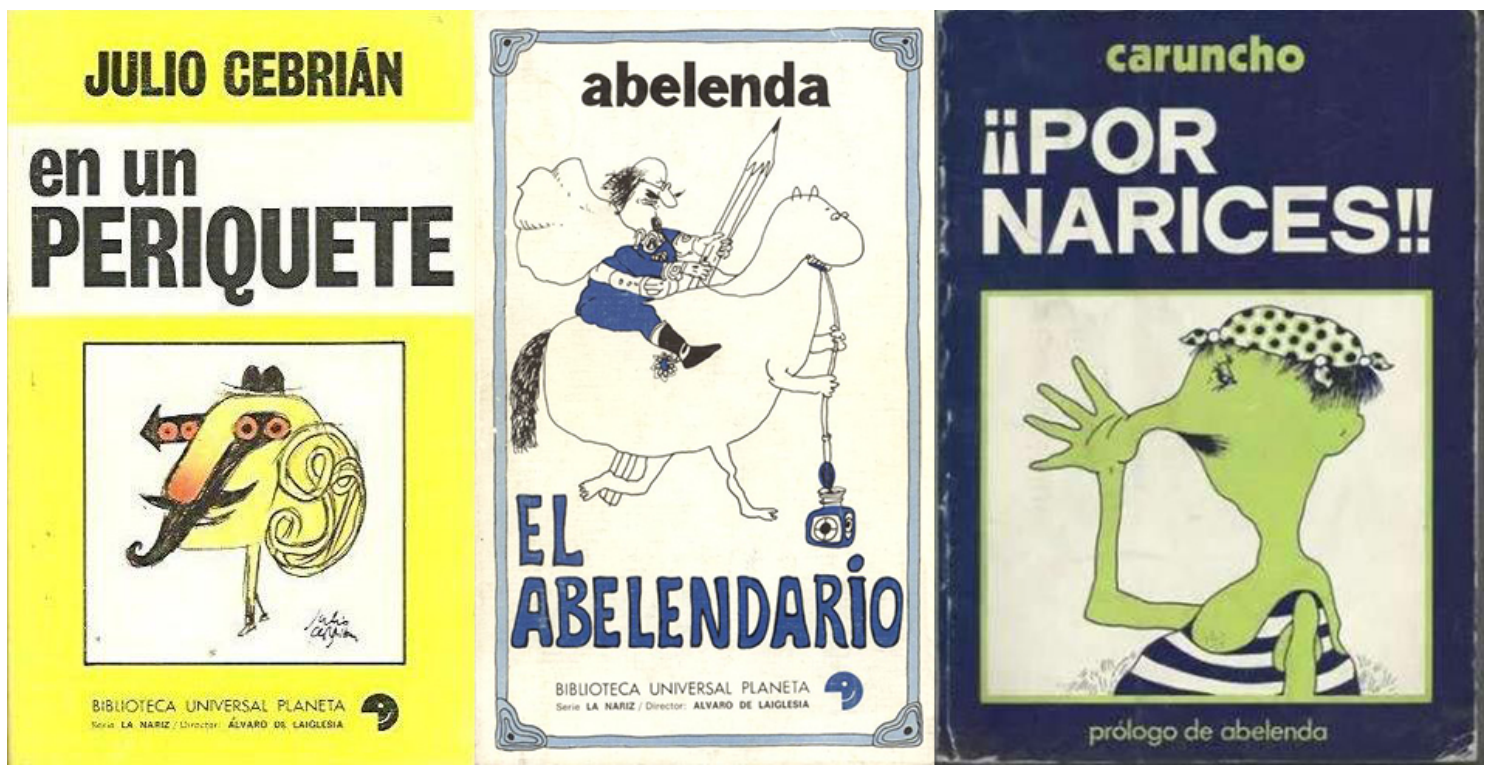

Figura 2. Antologías de Julio Cebrián, Abelenda y Caruncho de su trabajo en La Codorniz.

\subsection{Otros diarios y revistas de Madrid}

Aparte de colaborar los dos en Don José y La Codorniz, Julio Cebrián y Abelenda dibujaron para algunos de los diarios madrileños de la época (era un tiempo en que había una gran inflación de ellos, sorprendente a los ojos de hoy) y en buena parte de las principales revistas de la capital.

Respecto a los diarios, Cebrián trabajó para El Alcázar, Pueblo (que dirigía Emilio Romero) y Nuevo Diario (ND) (desde 1971, alternándose con Madrigal) y, después de la muerte de Franco, para Diario 16 y, ya en los años 90, El Mundo, la última publicación para la que dibujó de manera continuada. Por su parte, Abelenda colaboró en Arriba, $\mathrm{Ya}$, Informaciones (donde abordaba el chiste de actualidad, en alternancia con Tono y Madrigal) y Madrid (en el que se hizo cargo de la página de humor semanal con Moncho Goicoechea)3.

Por lo tanto, les une también el haber colaborado en los tres diarios que durante el tardofranquismo se caracterizaron por intentar llevar adelante una línea independiente y aperturista, pagando duramente por ello: El Alcázar, Nuevo Diario y Madrid.

A finales de los años 60, cuando Cebrián colaboró en él, El Alcázar estaba editado por Prensa y Ediciones (PESA), que defendía una actualización y una modernización de las

\footnotetext{
${ }^{3}$ Antes, mientras estuvo haciendo el servicio militar, colaboró en los diarios de Tetuán El Día y Diario de África.
} 
instituciones del régimen: más participación del pueblo y mayor representatividad. Su director por aquel entonces era José Luis Cebrián, de igual apellido que el dibujante, pero sin relación familiar con él. El diario pagó su audacia con la incautación por la Prensa del Movimiento: el 27 de septiembre de 1968, por orden gubernamental, volvió a manos de la Hermandad de Nuestra Señora Santa María del Alcázar, su primera editora, volviendo a acercarse a la línea dura del régimen. PESA editaba también durante un breve espacio de tiempo Nuevo Diario, en donde colaboró igualmente Cebrián.

Madrid, en el que colaboró Abelenda, se significó por su línea aperturista durante el tiempo en que estuvo controlado por Rafael Calvo Serer (presidente del consejo de administración) y Antonio Fontán (director). Dos artículos firmados por el primero expresan bien esa línea y provocaron las iras del régimen. El primero se publicó como editorial en el propio diario el 30 de mayo de 1968. Titulado "Retirarse a tiempo", con la analogía de la retirada del presidente de la República Francesa, el general Charles de Gaulle, mandaba un aviso a Franco para que se apartase al Pazo de Meirás. En el segundo, "Yo también acuso", publicado en Le Monde el 11 de noviembre de 1971, cuando su autor ya sabía que el Gobierno había decidido cerrar el periódico. Denunciaba que el régimen le intentaba imponer como director a José María Alfaro en sustitución de Fontán. Las luchas entre el accionariado reflejaban las disputas entre facciones del franquismo. El diario fue cerrado en 1971, y su sede social, dinamitada en 1978.

En cuanto a las revistas, Julio Cebrián colaboró también en La Actualidad Española, Crítica, Por Favor, Muchas Gracias, Monóxido 16 (semanario de Cambio 16), Interviú, A las Barricadas (suplemento humorístico de esta última cabecera) y Madriz. De su trabajo para Interviú ha dicho Siro:

El Cebrián de Interviú, con ochenta años cumplidos, me parece tan admirable como el de La Codorniz, porque es más expresionista, más surrealista y más vanguardista que nunca. Con ochenta años, Cebrián dibujaba y pintaba -nunca las viñetas fueron tanto dibujo y pintura- con la creatividad de un joven de veinte. Si el Cebrián de La Codorniz podía ser relacionado con Grosz, el de Interviú hace recordar al Bernini octogenario que, con trazos temblorosos, dibuja la impresionante caricatura del papa Inocencio XI, convirtiéndolo en un insecto (Siro4, 2016).

Por su parte, Abelenda colaboró en el semanario Cambio 16 y en las revistas Historia 16, Carta de España y Semana. Su último trabajo en prensa fue en Canal NW con la serie "Las historietas de Abelenda", réplica de las publicadas durante la Transición en Diario 16.

\footnotetext{
${ }^{4}$ Siro López Lorenzo, caricaturista, humorista gráfico, periodista y escritor gallego. Lo cito aquí solo por su nombre de pila, porque él ha manifestado repetidamente que desea que su producción escrita sea referenciada así, como siempre se ha hecho con su obra gráfica.
} 
Las colaboraciones de Cebrián en Madriz y de Abelenda en Cambio 16, las dos durante los años 80, nos permiten establecer otra interesante analogía entre ambos. Fueron, quizás, sus trabajos más notables. Tanto uno como otro hicieron cómic en estas revistas, que representaban la vanguardia social (Madriz) y política (Cambio 16) de la época. Los dos humoristas gallegos demostraron que seguían evolucionando y lo hicieron con una libertad como quizás no tuvieron nunca antes.

\subsection{Otros diarios y revistas de Madrid}

Julio Cebrián y Abelenda comparten también el hecho de haber ganado los dos el Premio Paleta Agromán5: Abelenda en 1967 y Cebrián en 1968. Abelenda recibió también la Primera Medalla en el II Salón Nacional de Humoristas en 1968 y el Premio Plomada Horizontal Agromán en 1986.

Considerado el Óscar nacional del humor gráfico, el Premio Paleta Agromán fue el galardón de humor gráfico más importante de España durante cinco décadas. Creado por la empresa constructora Agromán en 1958 y desaparecido en los años 90, vino a dar respaldo intelectual a este género. Tenía su origen en el almanaque sobre los logros y proyectos de la empresa que esta publicaba por Navidad todos los años a partir de 1941. Desde 1948 gran parte de sus contenidos consistían en viñetas de humor gráfico que se solicitaban a los mejores humoristas españoles. El también gallego Xaquín Marín ganó el premio dos veces, en 1982 y en 1991. Otros de los premiados fueron Madrigal (en tres ocasiones), Edu (en dos), Almarza (en otras dos), Tono, Ces, Ballesta, Chumy Chúmez, Máximo o Mena.

Por su parte, Caruncho recibió en 1975 medalla y placa de plata en la I International Cartoon Exhibition of Atenas.

\subsection{El estilo}

A la hora de comparar el estilo de estos tres humoristas vamos a centrarnos en su obra en La Codorniz. Desde el punto de vista gráfico, lo que les une es su preocupación estética. Ninguno es estrictamente un 'cartoonista' en el sentido que a veces se le da al 'cartoon' de dibujo descuidado hecho a prisa. Pero sus estilos son francamente diversos: mientras que Julio Cebrián practica un expresionismo cada vez más marcado, Abelenda y Caruncho realizan un dibujo de línea, dentro de una inquietud formalista, que en el primero alcanza un grado de preciosismo verdaderamente destacable.

\footnotetext{
${ }^{5}$ En 1983, con motivo del 25 aniversario del premio, se editó el libro AGUIRRE GONZÁLEZ, José María (1983). 25 años de humor español. Paleta Agromán / Óscar nacional del humor. Madrid: Stentor.
} 
La impronta del pintor en Cebrián ha sido destacada por Mingote, que dijo de él que "de todos los humoristas que soñamos con ser pintores, el mejor de nosotros ha sido y sigue siendo Julio" (Hernández-Cava, 2016), y también por Hernández-Cava (2016), para quien el orensano fue

una de las principales ínsulas en el humorismo español, un milagroso accidente dentro de las corrientes estéticas y pensantes con las que tuvo que convivir. Más próximo a las inquietudes pictóricas que a las que consideramos propias del monigotero, y con una preparación intelectual exquisita, fue empujado por las circunstancias a ejercer este noble oficio a la espera de su reconocimiento como artista plástico.

Para Tubau, la inquietud formal de Cebrián "le hace evolucionar por saltos bruscos y abominar de sus etapas pasadas". El grafismo de Cebrián -dice- "es de una riqueza y una audacia que rozan muchas veces lo impertinente. Lo que Máximo llama su 'desgarrado iberismo' se manifiesta a veces mediante nerviosos e intrincados trazos a bolígrafo, de un feísmo deliberado y desafiante, en otras ocasiones a través de una limpia y desnuda, sintética línea de asombrosa belleza" (Tubau, 1987: 150).

Según Siro (2016), “Cebrián fue un dibujante originalísimo, expresionista y surrealista a un tiempo y creador de un estilo personal, adecuado a su humor entre satírico y tierno".

El expresionismo de Cebrián aumenta a medida que pasan los años, como explica bien Llera:

... a medida que superamos el umbral de los primeros 60, su lenguaje formal se apoya en las líneas quebradas y en los ángulos agudos; se duplican los contrastes entre los blancos y los negros, el número de sombreados o rellenos a base de rayados o de aguadas. Po restas fechas su dibujo crece en deformación y en el dominio del gesto, acercándose a la estetica de pintores como Schiele, Grosz o Dix (Llera, 2003: 378).

Respecto a esta comparación con el alemán George Grosz (1893-1959), Siro (2016) dice que Cebrián "quizás no hizo más que convertir en creación artística la torpeza de los rasgos en los dibujos de la adolescencia. Después estudiaría a Grosz y a muchos otros dibujantes y pintores, hasta convertirse en un autodidacta culto".

El gallego huye conscientemente del dibujo bonito, llegando a un esteticismo plástico que adquiere valores propios al margen del chiste, hasta el punto de que muchas veces sus grafismos se convierten en entes autónomos, acompañados casi siempre por textos muy cuidados que ya no son chistes, sino reflexiones políticas, filosóficas o estéticas (Tubau, 1987: 149-150). 
Por su parte, el dibujo de Abelenda se caracteriza por su línea pura y su sentido de la composición. Según Tubau (1987: 187), "la línea, en Abelenda, parece manar del tintero como una cinta sin fin, solo interrumpida cuando el dibujante considera que ya ha dicho lo que tenía que decir. Y casi todas sus composiciones son asombrosas: parece imposible logar mayor concisión y riqueza a la vez, como al desgaire y como sin esfuerzo". El humorista opta casi siempre por una sencillez despojada en la que los personajes destacan sobre los demás elementos del dibujo, pero sin estar en el aire, sino situados en ambientes bien caracterizados.

Para Luís Seoane, Abelenda es "uno de los dibujantes más destacados de España". Así hablaba de él en el capítulo que le dedicó dentro de su serie "Figuraciones", publicado originariamente en el diario La Voz de Galicia de A Coruña el 9 de febrero de 1975. Seoane elogiaba "su preocupación acerca de los aspectos formales del dibujo" también como dibujante de humor: "Se trata de un dibujante que gusta del dibujo, algo que es muy distinto a lo que se llama "caricaturista", género aparte de autores de monos [en el sentido que le da el DRAE: "Dibujo rápido y poco elaborado"] que se ha desacreditado en los últimos 20 o 30 años por su falta de preocupación por los problemas formales del dibujo".

En Caruncho encontramos también un delicado dibujo de línea que quizás deba algo al de su amigo Abelenda, aunque resulte menos preciosista, más simple, y que contrasta con el explosivo cóctel de humor negro y surrealismo del contenido. Llaman la atención los rostros de los personajes, con ojos con los párpados y las pestañas marcados y narices triangulares como zanahorias. La mayoría de sus viñetas son mudas, el $70 \%$ (más de dos de cada tres) de las recogidas en la antología iPor narices! Abelenda también practica el dibujo sin palabras, pero en menor proporción: el 21\% (una de cada cinco) de los de El abelendario.

Si la similitud formal de los tres humoristas no pasa, más alla de las concomitancias entre Abelenda y Caruncho, de la preocupación estetica de todos ellos -una preocupación de la que también participan otros humoristas gallegos de la época que colaboran en la prensa de Madrid, como Quesada o Marín, heredada, quizás, de Castelao y los dibujantes de su tiempo (Maside, Cebreiro, Torres, Ribas, etc.)-, las concomitancias desde el punto de vista del contenido (o, mejor, de la actitud) son mayores.

En los tres observamos una ironía velada no exenta, en ocasiones, de sarcasmo, características que suele atribuirse al humor gallego. También cierto humor negro, que suele asociarse, igualmente, a la idiosincrasia gallega. Dos de los capítulos de El abelendario -el libro se divide en once- se refieren a "La violencia" y "Los suicidas", lo que anuncia ya en parte este humor negro. $Y$ en Caruncho abundan las viñetas con cuerpos mutilados. Los tres participan también de la crítica sociológica-moral con la que relaciona Tubau a Abelenda en El humor gráfico en la prensa del franquismo. La agresividad temática de las viñetas de Abelenda contrasta con su dibujo suave y 
redondeado. También la de Caruncho con respecto a su dibujo de línea. No tanto la de Cebrián, por su expresionismo. Los tres se concentran casi siempre en el agudo retrato del burgués biempensante del tardofranquismo, al que fustigan con comicidad: "-Piénselo, Rodríguez : le doy veinte mil mensuales si se hace cargo de mis objeciones de conciencia” (Cebrián); "-En nuestras manos está el hacer el bien, de consumo, por supuesto" (Abelenda) ; "-Nosotros también tenemos caja de resistencia , pero en Suiza. -Y bien grande" (Caruncho).

Caruncho añade a sus viñetas un surrealismo, o un absurdo, que no está tan presente en la obra de sus paisanos. Pensemos, por ejemplo, en una en la que se ve a un hombre sentado en una silla con un pie por cabeza y la cabeza por el pie. $O$ otra en la que un conejo saca a un mago de una chistera. O una tercera en la que aparece un hombre sentado en una silla con una gran maceta en brazos, y la maceta le dice: "Cuándo se convencerás de que lo nuestro es absurdo". Sorpresa y cambio de roles.

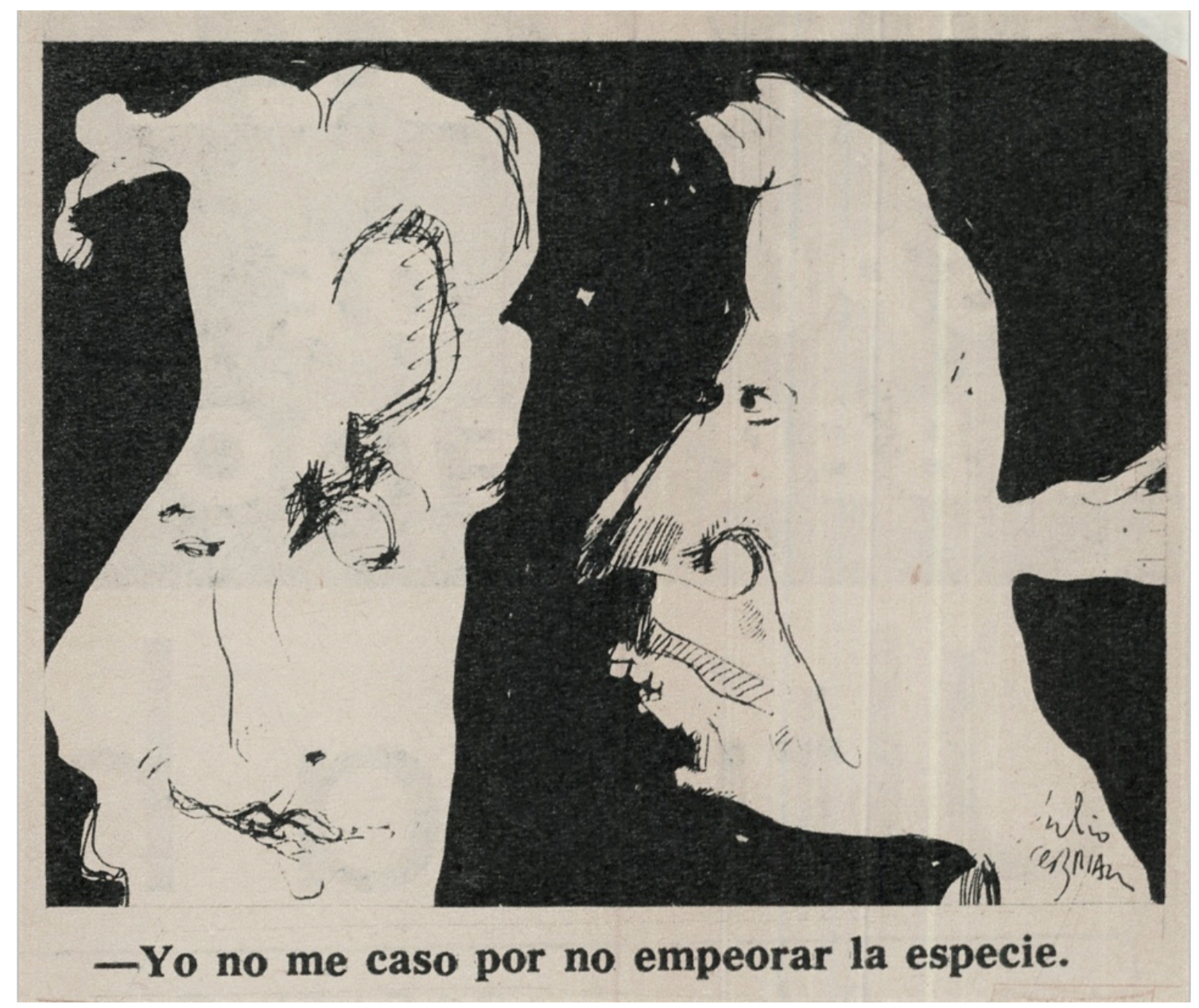

Figura 3. Julio Cebrián, La Codorniz, 1.590, 8-5-1972. 


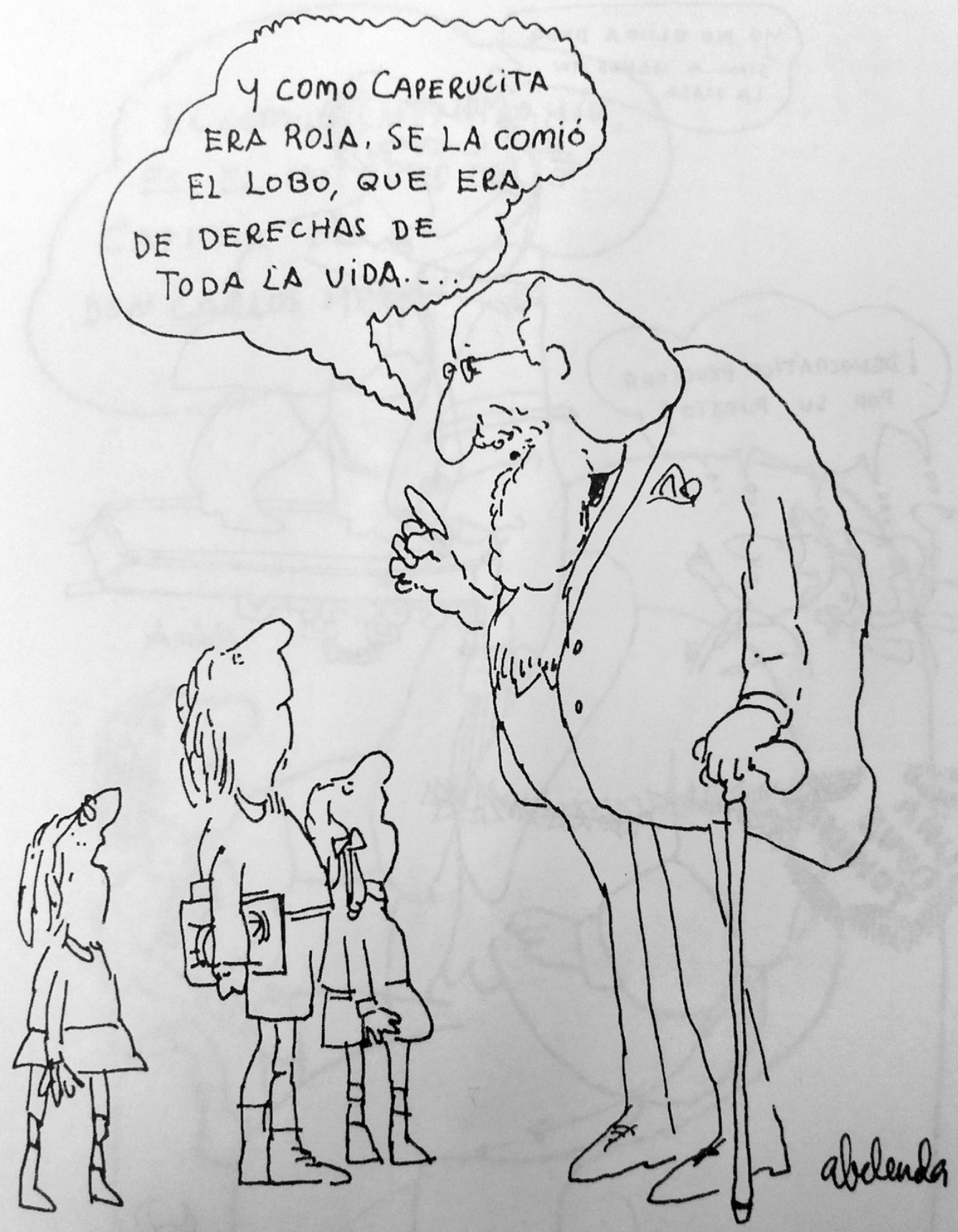

Figura 4. Abelenda, El abelendario... 40 años después. 


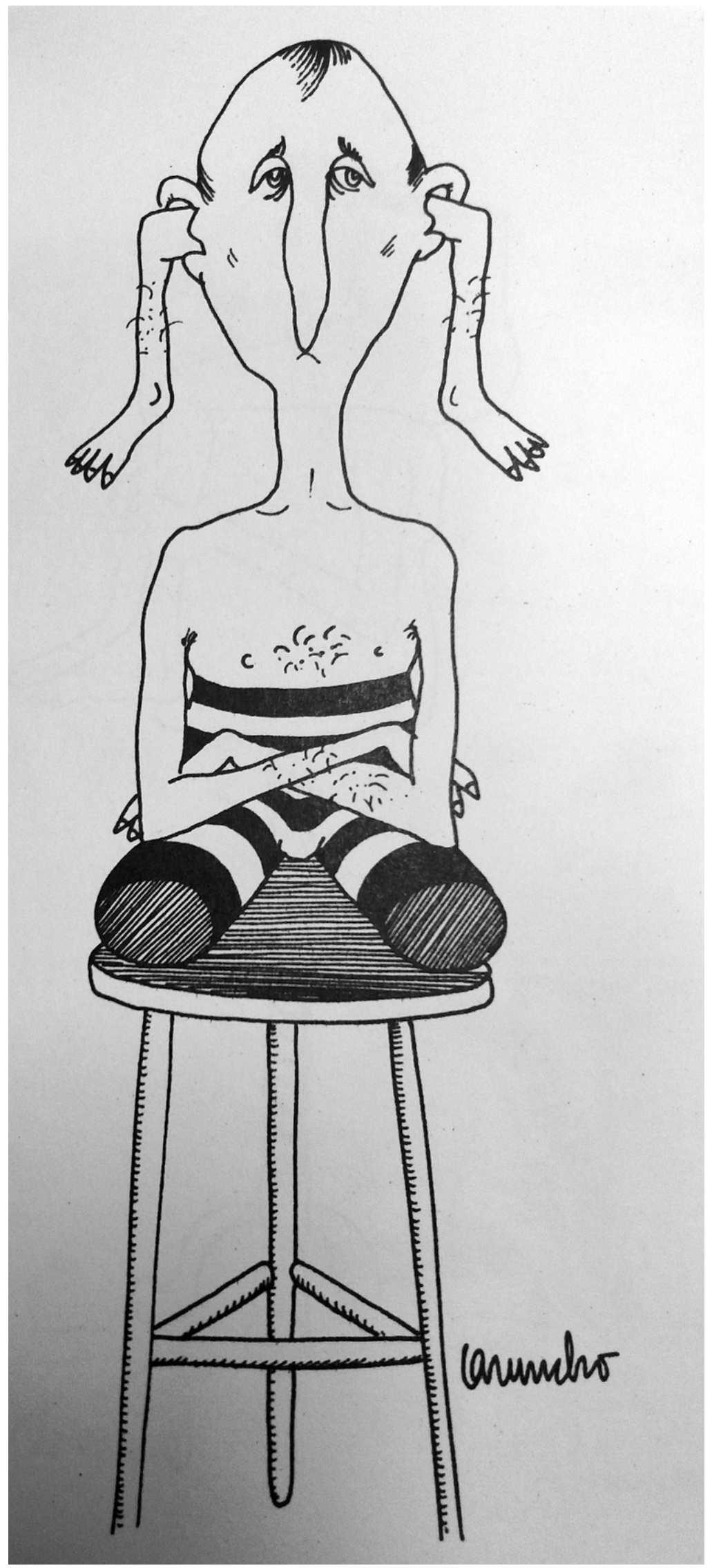

Figura 5. Caruncho, iPor narices! 


\section{Conclusiones}

En los años 60, 70 y 80 fueron varios los humoristas gallegos que colaboraron con la prensa de Madrid. Julio Cebrián, Abelenda y Caruncho fueron tres de los más relevantes, llegando a ser, sobre todo los dos primeros, sostenes principales de La Codorniz.

Los tres fueron, fundamentalmente, pintores y practicaron el humor gráfico por motivos más o menos crematísticos, pero llegaron a alcanzar en este terreno una dedicación y una importancia muy grandes, especialmente Cebrián y Abelenda.

Los paralelismos y cruzamientos son mayores entre estos dos, que tenían edades similares y le llevaban casi 20 años a Caruncho: los dos se iniciaron en Don José a mediados de los años 50; los dos colaboraron en el tardofranquismo en algunos de los diarios y las revistas más importantes de Madrid, incluidos algunos periódicos que llevaron adelante una línea aperturista que pronto se vio malograda (Cebrián en El Alcázar de Pesa; Abelenda en el Madrid de Calvo Serer); los dos ganaron el Premio Paleta Agromán; y los dos dibujaron cómics en los años 80 en dos de las revistas más significativas de la época (Cebrián en Madriz, que representaba la modernidad social, y Abelenda, en Cambio 16, que encarnaba la apertura democrática).

En cuanto a la forma, a los tres les une una evidente preocupación estética, pero hay que diferenciar entre el expresionismo creciente de Cebrián y el formalismo de Abelenda, sobre todo, y Caruncho.

Más similitudes presentan respecto al contenido, tanto a la temática, con especial atención al burgués biempensante del tardofranquismo, como a la actitud, que podemos resumir en tres elementos: ironía velada no exenta de sarcasmo, crítica sociológica-moral y cierto humor negro.

\section{Referencias bibliográficas}

ÁLVAREZ, J.T. (2012): Historia y modelos de comunicación en el siglo XXI, Madrid, Universitas (estilo_RiHC_Bibliografia)

- (2001): "Feria y turismo en Málaga. El papel de la prensa y de la opinión pública en la consolidación de un proyecto ciudadano (1884-1936)", en Arias, E., Barroso, E., Parias, M. y Ruiz, Ma J. (editores), Comunicación, Historia y Sociedad, Sevilla, Universidad y Ayuntamiento de Sevilla, pp. 433-444. (estilo RiHC_Bibliografía_LibrosAdicionales). 
PIZARRO QUINTERO, A. (1998): “Guerra, cine e historia. La guerra de 1898 en el cine" en Historia y comunicación social, nำ, 1998, pp. 143-162.

BENAVIDES DELGADO, J. (1995): "La presencia de la publicidad en la construcción de la cultura cotidiana" en Especulo. Revista de estudios literarios, nำ, noviembre de 1995. Disponible en Internet (4-12-2002): http://www.ucm.es/info/especulo/numero1/benavid.htm

ABELENDA, A. (1972): El Abelendario, Barcelona, Planeta, Serie La Nariz, 11. - (2013): El Abelendario. 40 años después, A Coruña, Arenas.

BUGALLAL, I. (2008): "Álvaro Caruncho: 'Los humoristas de La Codorniz eran gente muy rara". La Opinión A Coruña, 14 de febrero. Recuperado el 1 de junio de 2019 de https://www.laopinioncoruna.es/contraportada/2668/humoristas-codornizgente-rara/166146.html

CABALLERO, F. (2018): Xaquín Marín. Arte e compromiso no humor gráfico galego, Vigo, Galaxia.

CARUNCHO, A. (1977): iPor narices!, A Coruña, Moret.

CEBRIÁN, J. (1973): En un periquete, Barcelona, Planeta, Serie La Nariz, 19.

Ficha de Abelenda en Humoristán. Recuperado el 1 de junio de http://humoristan.org/es/autores/abelenda/

Ficha de Abelenda en Tebeosfera. Creación: Félix Cepriá e Ismael Sobrino, 2008. Recuperado el 1 de junio de 2019 de https://www.tebeosfera.com/autores/abelenda_escudero_alfonso_pedro.html,

Ficha de Caruncho en Tebeosfera. Creación: Andrés Álvarez e Ismael Sobrino, 2013. Recuperado el 1 de junio de 2019 de https://www.tebeosfera.com/autores/de_la_iglesia_caruncho_alvaro.html

Ficha de de Julio Cebrián en Tebeosfera. Creación: Juan Manuel Bosque Sendra y Manuel Barrero, 2009. Recuperado el 1 de junio de 2019 de https://www.tebeosfera.com/autores/cebrian_villagomez_julio.html.

Ficha de Julio Cebrián en Humoristán. Recuperado el 1 de junio de 2019 de http://humoristan.org/es/autores/julio-cebrian/

HERNÁNDEZ-CAVA, F. (2016): “Muere Julio Cebrián, el mejor de los dibujantes que soñaban ser pintores". El Mundo, 3 de noviembre.

LLERA, J. A. (2003): El humor verbal y visual de 'La Codorniz', Madrid, CSIC. 
MADRIGAL, A. (2016): "Valioso pintor y humorista surreal”. El País, 15 de noviembre, p. 43.

MALLO, A. (2001): "Alfonso Abelenda", en Pulido, A. (dir.), Artistas galegos. Pintores. Realismos, expresionismos, abstraccións, Vigo, Nova Galicia, pp. 74-214.

PENAS, A. (2008): Abelenda, A Coruña, Diputación de A Coruña, Serie Grandes Pintores.

PEREIRA, N. (2014): “Alfonso Abelenda: dibujante, pintor y actor, descendiente de María Pita". El blog de Nolito Pereira, 9 de enero de 2014. Disponible en internet (1-62019): http://nitope.blogspot.com.es/2014/01/alfonso-abelenda-dibujante-ypintor.html

PRIETO, M. y MOREIRO, J. (ed.) (1998): La Codorniz. Antología (1941-1978), Madrid, EDAF.

SIRO (2016): "Humorista gráfico de talento inesgotable". La Voz de Galicia, 4 de noviembre.

TUBAU, I. (1987): El humor gráfico en la prensa del franquismo, Barcelona, Mitre. 